\section{Uso de sinais de pontuação na construção dos sentidos textuais}

\author{
Use of punctuation marks in the construction of textual \\ meaning
}

\section{Antonio Cesar da Silva (i) 9}

ancesil16@gmail.com

Universidade Estadual de Alagoas - UNEAL

\section{Maria Inez Matoso Silveira (D) 9}

mimatoso@uol.com.br

Universidade Federal de Alagoas - UFAL

\section{Resumo}

O estudo sobre o uso dos sinais de pontuação na construção dos sentidos textuais aqui proposto reflete sobre a interferência desses recursos de escrita na marcação de posturas enunciativo-discursivas em textos jornalísticos. Observações feitas a partir do corpus analisado mostraram que alguns sinais de pontuação, em circunstâncias específicas de uso, não exercem função em relação à estrutura sintática do texto. Neste artigo, em especial, analisa-se o uso de dois sinais: travessões e parênteses. A partir dessa constatação, investigaram-se as funções que determinados recursos de pontuação são capazes de promover num enunciado, uma vez que seria nula sua função sintática. A pesquisa fundamenta-se, principalmente, nos estudos de Catach (1994), Junkes (2002) e Dahlet (2006). O estudo caracteriza-se como uma pesquisa qualitativa baseada na análise de corpus, este, por sua vez, constituído por fragmentos de textos jornalísticos recolhidos de portais digitais. Os resultados mostram o uso eficiente de pontuação assinalando posturas enunciativo-discursivas em fragmentos para os quais os aspectos puramente sintáticos não seriam efetivos nem produtivos.

\section{Palavras-chave}

Sinais de pontuação; Discursividade; Sentido.

\section{Abstract}

The study of the use of punctuation signs in the construction of textual meanings proposed here reflects upon the interference of those resources in marking of enunciative postures in journalistic texts. Observations made from the analysed corpus show that some punctuation marks, used in specific circumstances, do not function in relation to the syntactic structure of the text; in this article, specially, it's analyzed the use of two signs: em dashes and parenthese. As of this acknowledgement, the role that determined punctuation resources would play in a textual statement began to be investigated, once that their syntactic function would be non-existent. The research mostly bases itself in the studies of Catach (1994), Junkes (2002) and Dahlet (2006). The study characterizes itself as qualitative research based on the corpus analysis, that's built out of fragments of journalistic texts collected from digital outlets. The results show the effective use of punctuation signing discursive postures on fragments, in which the purely syntactic aspects would not be effective or productive.

\section{Keywords}

Punctuation marks; Discourse; Meaning.

\section{Linguagem Foco}

Revista do Programa de Pós-Graduacão em Linguistica Aplicada da UECE

FLUXO DA SUBMISSÃO

Submissão do trabalho: 10/11/2020 Aprovação do trabalho: 04/12/2020 Publicação do trabalho: 22/01/2021

\section{COMO CITAR}

SILVA, Antonio Cesar da; SILVEIRA, Maria Inez Matoso. Uso de sinais de pontuação na construção dos sentidos textuais. Revista Linguagem em Foco, v.12, n.3, 2020. p. 361-382. Disponível em: https://revistas.uece. $\mathrm{br} / \mathrm{index}$.php/linguagememfoco/article/view/4372. 


\section{Introdução}

O interesse pelo estudo dos sinais de pontuação como recurso de escrita na construção dos sentidos textuais surgiu durante as atividades de ensino dos autores deste trabalho como professores de Língua Portuguesa em aulas da educação básica e do ensino superior. De modo geral, deparamo-nos com explicações sobre tais recursos que não eram suficientes, nem como justificativa de sua natureza linguística nem como critério de sua aplicabilidade. A insuficiência da justificativa e a imprecisão dos critérios manifestavam-se nas abstratas indicações de uso que diziam, por exemplo, que a vírgula deveria ser usada para marcar uma pausa curta em comparação com o ponto e vírgula, utilizado para sinalizar uma pausa maior que a indicada por aquela.

Essa inquietude aumentava quando, nas situações de uso ou nas propostas de conceituação e de apresentação das razões de utilização dos sinais de pontuação, percebíamos que o "critério-cronômetro" era colocado de lado e passava-se a tomar como referência aspectos da estrutura sintática do texto. Nesse sentido, orientações como as que indicavam o uso de vírgula para separar termos de mesma função sintática, ou para intercalar expressões explicativas como aposto e orações adjetivas pareciam fazer mais sentido do que aquelas que apontavam para a necessidade de marcação de pausas e do ritmo de leitura.

Neste artigo, nossas investigações têm o interesse de demonstrar como alguns tipos específicos de pontuação, em circunstâncias igualmente específicas de uso, transformam-se em recursos diretamente ligados à construção dos sentidos textuais, revelando-se, inclusive, sem efeitos em relação à organização sintática da estrutura frástica. Para demonstrar tal propriedade verificada nos usos de alguns sinais de pontuação, escolhemos trabalhar com textos pertencentes ao gênero textual notícia postados em portais jornalísticos. A seleção dos textos e dos fragmentos para análise aconteceu na medida em que foram sendo identificadas as ocorrências que apresentavam fenômenos pertinentes ao propósito estabelecido. Delimitados esses aspectos, foram selecionados 28 textos, que compuseram o corpus de pesquisa e dos quais foram extraídos os fragmentos analisados neste artigo. Ressaltamos, no entanto, que, em função de suas delimitações metodológicas e objetividade do gênero, selecionamos apenas dois fragmentos para análise, nos quais se observará a ocorrência de dois tipos de

1 Com essa expressão, referimo-nos à forma como alguns manuais gramaticais associam o uso dos sinais de pontuação à duração da pausa que, supostamente, os sinais de pontuação traduzem durante o processo de leitura. 
sinais com funções essencialmente enunciativo-discursivas: travessões e parênteses. Esses dois tipos de sinais manifestam, nos fragmentos selecionados, características de uso identificadoras dos fenômenos investigados.

Quanto à abordagem teórica adotada para o tratamento linguístico das análises, ela está fundamentada, principalmente, nos estudos de Catach (1994), Junkes (2002) e Dahlet (2006), especialmente no que diz respeito à categorização e às funções dos sinais de pontuação, cujas aplicações não se justificam do ponto de vista dos aspectos sintáticos do segmento frasal em que eles aparecem. Além desses estudos, são acessados também para compor a fundamentação teórica em relação ao que remete aos aspectos enunciativo-discursivos, a concepção de atos de linguagem de Charaudeau (2014) e os estudos da linguística pragmática de Searle (1995), particularmente no tocante à manifestação de estados intencionais. Acreditamos que o acesso aos princípios e pressupostos teóricos defendidos por esses teóricos proporcionará análises pertinentes sobre as funções enunciativo-discursivas exercidas por travessões e parênteses que se transmutam em verdadeiras marcas enunciativo-discursivas de pontuação. Todas essas abordagens estão antecedidas por uma revisão dos processos de formação e da evolução histórica desses recursos de escrita.

\section{A constituição dos sinais de pontuação}

Não se questiona que a relação e a influência da fala na estruturação e organização da escrita se deve, ao menos a princípio, à própria história de formação desta que ganhou existência na perspectiva de ser falada, na medida em que os textos escritos eram produzidos para serem lidos em voz alta. Vale lembrar que os gregos - sistematizadores da escrita - não conheciam a leitura silenciosa, "e o leitor de um texto falava as palavras em voz alta, mesmo quando estava lendo sozinho" (TRASK, 2008, p. 232). Em razão disso, durante o processo de formação da escrita grega, passou-se a acrescentar marcas (sinais) que fizessem o leitor lembrar (no momento da leitura) onde se deveria fazer uma pausa ou elevar o tom de voz.

Essa influência de aspectos da fala sobre a escrita é uma das razões pelas quais esta última sempre foi vista como uma materialização daquela sem nenhum sentido lógico-gramatical, indicando que a pontuação não passava "meramente de uma transmutação histórica de aspectos oriundos da fala que se teriam, sistematicamente, reanalisado e recodificado, dissociando-se de sua base 
generativa" (MACHADO FILHO, 2004, p. 24). Fica claro que os sinais de pontuação - até como parte do processo de formação e desenvolvimento da escrita - caracterizam-se como uma tentativa de representação de aspectos da fala. No entanto, compreende-se que "esse pressuposto teórico, além de bastante questionável, corre o risco de enganar, pois deixa acreditar que o escrito compartilha parâmetros similares com o oral, quando não parâmetros do próprio oral" (DAHLET, 2006, p. 24).

A partir dessa observação, é preciso considerar que o uso dos recursos de pontuação tem motivações próprias e fundamentos fincados na sistematização de aspectos sintático-textuais e/ou enunciativo-discursivos caracterizadores da própria modalidade escrita da língua. Nesse sentido, a gênesis do desenvolvimento da escrita e, por conseguinte, dos sinais de pontuação, deve ser considerada a partir das contribuições da civilização helênica, na qual se registra um paulatino processo de aprimoramento não só dos aspectos gráfico-alfabéticos - como a inserção das letras representativas dos sons vocálicos -, bem como da própria forma de organização do texto sob a superfície física em que se apresentava. Por essa razão, registra-se:

\footnotetext{
A escrita alfabética grega começou como uma sequência de letras, sem espaços e sem pontuação. A primeira linha era da esquerda para a direita; quando o escritor chegava no final da linha, ele descia, mais ou menos, a altura de uma letra e voltava da direita para a esquerda, depois da esquerda para direita novamente, e assim por diante em linhas alternativas² (HALLIDAY, 1989, p. 32).
}

As características e os aspectos presentes na expressão escrita são o resultado de séculos de uma evolução principiada, basicamente, no seio das manifestações culturais da civilização helênica. A mais significativa dessas contribuições é, segundo Houaiss (1983), a inserção de um "espaço branco funcional" entre as palavras de uma sentença. Isso representou um passo importante no desenvolvimento e no estabelecimento do sistema de pontuação. O processo que resultou na formação e constituição de aspectos lógicos presentes no sistema de pontuação, afastando-o do papel de mera representação de aspectos da fala, principiou-se com a utilização de um ponto variável chamado ponto de altura. Esse sinal usado entre as palavras de uma sentença, a depender da posição em relação à última palavra (na base da palavra, no meio ou acima dela), indicaria o tipo de

2 Greek alphabetic writing began as a string of letters, without spaces and without punctuation. The first line usually from left to right; when the writer reached the end of the line, he went down about the height of one letter went back along the line from right to left; then left to right again, and so on with alternate lines" (Tradução livre) 
pausa (breve, média ou longa) que o leitor de um texto deveria aplicar. No caso de ser colocado, no alto da palavra, por exemplo, corresponderia ao fim do período (pausa longa). Ainda, segundo Houaiss (1983):

Num segundo estágio, principiou-se a distinguir, de novo, por um ponto em altura variável, a separação do que corresponde grosso modo à noção atual do parágrafo. Terceiro estágio é o dos gramáticos, filólogos, glosadores alexandrinos, que principiaram a intercalar signos de pausa respiratória, numa aproximação do débito declamatório do texto [...] (HOUAISS, 1983, p. 90, grifo do autor).

Seguindo o processo de evolução e aprimoramento do sistema de pontuação, a Idade Média registra a continuidade daquilo que foi desenvolvido especialmente pelos alexandrinos. Já "o Renascimento se limitou a herdar, em linhas essenciais, os principais signos de pontuação modernos, embora empregando-os num sentido progressivamente lógico-gramatical, enquanto antes se fazia preferentemente subordinado ao perfil melódico da cadeia da fala e das pausas" (HOUAISS, 1983, p. 90). É importante notar que, como recurso lógico-gramatical, o sistema de pontuação na Idade Média, mais precisamente entre os séculos XI e XII, apresentou desdobramentos a partir da introdução do ponto de segmentação do discurso, usado inicialmente para marcar a divisão principal do texto. Nesse período, "o sistema de pontuação tende a se desenvolver e a se generalizar, com o ponto (que marca a escansão principal), o ponto e vírgula e o ponto sobreposto de um acento circunflexo [...]" (BARBIER, 2008, p. 87).

Verifica-se que, nesse período, ainda segundo Barbier (2008), o sistema foi alargando-se, inserindo sinais de pontuação que indicavam interferências leves na estrutura organizacional do texto, ou na maneira de lê-lo. Uma dessas marcas foi a barra oblíqua (/), que mais tarde transformou-se na vírgula ("varinha", segundo algumas etimologias), usada atualmente como marca mais frequente de organização sintática.

\footnotetext{
A inovação principal nascerá em seguida nos meios humanistas italianos, onde são progressivamente utilizados o ponto de exclamação e os parênteses (início do século XV). Esse conjunto será em sua essência conservado nos primeiros livros impressos (BARBIER, 2008, p. 87).
}

Note-se que, desde a formação e estruturação do sistema de pontuação que se tem hoje, registra-se a presença de recursos de pontuação indicadores de processos que ultrapassam os aspectos sintáticos e estruturais do texto. Como se pode ver, inclusive, entre tais recursos, encontram-se os parênteses - um dos dois sinais analisados neste artigo. 
Para além dessas particularidades, sabe-se que muitas das características presentes ainda hoje no modo ocidental de registrar a expressão escrita estão relacionadas com o advento da Escrita Carolina. Foi também por conta da padronização promovida nesse período que as muitas e variadas formas de pontuação de um texto começaram a ser reduzidas. Nesse sentido, enquanto reforma do sistema de escrita, ela representou uma revolução com a introdução, por exemplo, da minúscula Carolina que se apresentava mais arredonda, regular e bem separada - evitando a subjetividade do traço do escriba e/ou do copista -, o que garantia maior inteligibilidade do texto escrito.

Especificamente em relação ao uso de sinais de pontuação a Escrita Carolina trouxe a regularização das marcas como uma tentativa de uniformização dos usos. Sabe-se ainda que "com o advento da Escrita Carolina o uso de sinais de pontuação restringiu-se, quase sempre, ao ponto" (MACHADO FILHO, 2004, p. 51). A ênfase dada a essas particularidades e distinções, até aqui, tem o objetivo de salientar o afastamento significativo dos sinais de pontuação dos aspectos prosódicos, desvinculando-os da associação a recursos da oralidade.

Nesse sentido, é curioso notar que, modernamente, há uma tendência em associar (sobretudo em livros didáticos e manuais gramaticais) o uso dos sinais de pontuação a uma compreensão que já havia sido superada antes mesmo da invenção da imprensa, que, por sinal, trouxe ainda mais inovações em relação à forma de conceber e aplicar tais recursos de escrita.

\section{Uso de sinais de pontuação na construção dos sentidos textuais - do sintá- tico ao discursivo}

Para além do processo de evolução e de tudo que possa ter contribuído para a formação do sistema de pontuação, pode-se dizer que os princípios que regem seus critérios de aplicação dizem respeito a três aspectos justificadores de sua presença num texto, quais sejam: a) os aspectos sintáticos; b) os rítmico-melódicos; c) os enunciativo-discursivos. Esses aspectos refletem características que marcam fortemente a expressão escrita e associam-se na construção dos sentidos dos enunciados e, por conseguinte, na compreensão desses sentidos por parte daqueles que leem os textos - seja em voz alta, seja silenciosamente. Atente-se para o fato de que até mesmo os aspectos entoativos e rítmico-melódicos (entendidos, aqui, como consequência da presença do recurso de pontuação) desempenham importante função na construção dos sentidos do texto, pois, uma vez que não se leia o enunciado com a postura entoacional e rítmico-meló- 
dica que ele exige, corre-se o risco de o enunciado não ser compreendido, ou ser percebido diferentemente daquilo que o escrevente quis marcar. Por essa razão, algumas vezes, é preciso ler e reler - inclusive em voz alta - para compreender o que se expressa. Assim, considera-se que as funções dos recursos de pontuação podem ser analisadas segundo esses três aspectos e segundo as dimensões que Ihes estão implicados na construção dos sentidos textuais. Catach (1994) sintetiza todas essas relações dos mecanismos sintáticos da seguinte forma:

Uma unidade sintática deve ser compreendida como envolvendo uma associação de palavras (aspecto estrutural), uma mensagem (aspecto informacional), uma substância e uma forma entonativa (aspecto melódico e entoativo) e um sentido (contendo a mensagem, resultante de todos os dados anteriores) (CATACH, 1994, p. 48).

Assim, como parte do sistema que organiza os segmentos textuais, os sinais de pontuação - como tudo que compõe as relações de sentido de um enunciado concreto - não devem ser vistos apenas a partir dos seus aspectos sintáticos, muito menos, ainda, restritos aos efeitos que imprimem ao processo de leitura. Para além de tudo isso, é preciso reconhecer também que "os elementos e as funções da pontuação nem sempre estão claros para os usuários da língua: as dificuldades em relação ao seu emprego resultam também de fatores externos à estrutura da língua, que nem sempre a gramática tradicional considera" (JUNKES, 2002, p. 60). Portanto, é necessário fazer entender, sobretudo durante os processos de aquisição da escrita, que a pontuação que se aplica a um texto justifica-se quando ele é tomado como um todo, como uma grande unidade de sentidos. É nessa totalidade que as funções enunciativo-discursivas, desempenhadas pelos sinais de pontuação (objeto de interesse aqui), revelam-se.

Reconhecidas essas implicações, é preciso fazer referência à forma como, em geral, esses recursos de escrita são abordados em situações de aprendizagem da modalidade escrita da língua. Muitas vezes, a compreensão de suas funções restrita aos aspectos sintáticos não permite perceber, durante o processo de leitura, diferenças sutis, mas pertinentes e significativas para compreensão e interpretação do que se enuncia. Assim, durante o processo de formação escolar, no que diz respeito ao tratamento dado aos sinais de pontuação, faz-se necessário que se abordem suas funções enunciativo-discursivas com a mesma objetividade e sistematicidade com que se expõe e se estuda seu papel sintático. É nesse sentido que Junkes (2002) afirma:

Estudiosos do discurso, hoje, veem a pontuação em uma perspectiva mais ampla 
que a da unidade frasal, tal como compreendida pela gramática normativa. Passa-se a encarar a pontuação no interior do parágrafo, como uma unidade no corpo do texto. Mesmo sendo a normalização de uso consequência da institucionalização da escola, que estabelece a unidade nacional, ela deve exercer um papel atualizador, isto é, ocupar a função que corresponde à sua melhor carga comunicativa (JUNKES, 2002, p. 60).

Quando se projeta tudo isso sobre os processos de ensino e aprendizagem da modalidade escrita da língua, entende-se a urgência de os estudantes serem orientados, desde seus primeiros contatos com a expressão escrita da língua, a compreenderem que os recursos de pontuação podem expressar muito mais que delimitações sintáticas ou orientações rítmico-melódicas na leitura do texto. Por essa razão, a escola deve apresentar-Ihes a carga comunicativa inerente aos sinais de pontuação, reconhecendo, inclusive, que em algumas circunstâncias o aspecto sintático poderá ter pouca produtividade, ou até mesmo ser nulo em relação aos sentidos do texto. Isso evidenciará que a razão de aplicação do sinal de pontuação será, necessariamente, de outra ordem, qual seja: a esfera da discursividade.

Um exemplo de nulidade sintática de uso específico dos sinais de pontuação ocorre com as vírgulas que intercalam orações adjetivas explicativas (como se vê no fragmento 1, abaixo). Nesse caso, tem-se um fenômeno bastante referenciado em aulas e materiais didáticos de Língua Portuguesa; no entanto, em geral, enfatiza-se apenas a distinção taxonômica, que opõe o tipo de adjetiva explicativa (entre vírgulas) ao tipo de adjetiva restritiva (sem vírgulas). Em geral, quando se está diante dessa situação de uso de vírgula, destaca-se o aspecto menos significativo e menos produtivo do enunciado. Por outro lado, a dimensão enunciativo-discursiva, que é a razão pela qual se aplicam (ou não) as vírgulas nesses casos, não é referenciada; o que acaba sendo lamentável, pois este último aspecto incidirá na compreensão e interpretação do que se enuncia pela intercalação da oração adjetiva entre vírgulas. Nessa situação de aplicação dos sinais de pontuação, o que se deveria destacar seria o fato de as vírgulas indicarem a presença de uma redundância, ou de uma generalização em relação à expressão referenciada. Quando da ausência das vírgulas, deve ser inferida uma especificidade, isto é, uma particularidade do sentido da expressão referenciada. Na análise do fragmento 1, abaixo, é possível demonstrar esses fenômenos:

(1) "Eis o início dos conceitos de topologia, que hoje embasam praticamente todos os trajetos de mapas de metrô do mundo, para 
comunicar claramente aos usuários o que eles necessitam saber: como chegar aonde querem ir" (BBC News Online, 2019).

A oração intercalada por vírgula (destacada em itálico) é, automaticamente, identificada como oração subordinada adjetiva explicativa. Como já salientado, a presença das vírgulas não desempenha nenhuma interferência na estrutura sintática do fragmento. $\bigcirc$ uso desse par de vírgulas aponta, portanto, para a natureza enunciativo-discursiva do conteúdo da oração intercalada em relação à expressão determinada por ela. Nesse caso, especificamente, as vírgulas sinalizam a presença de uma postura generalizante, que, curiosamente, aparece assinalada no próprio enunciado através das expressões: "praticamente todos [...]". Sem as vírgulas (se fosse o caso), seria apontada uma "restrição", uma especificação da aplicação dos "conceitos de topologia", o que poderia ser desdobrado como algo do tipo: "Eis o início dos conceitos de topologia que hoje embasam [apenas alguns] trajetos de mapas de metrô do mundo [...]". Considere-se, portanto, que a ausência das vírgulas tornaria incoerente, no texto-fonte, a expressão "praticamente todos". Diante desses aspectos, o que deveria ser sempre enfatizado, no estudo desse tipo de ocorrência, seria o fato de a presença (ou a ausência) das vírgulas serem uma decorrência dos sentidos presentes naquilo que se enuncia através das orações adjetivas, isto é, um recurso enunciativo-discursivo de pontuação. Tudo isso resultante do processo de transmutação evidenciado pela nulidade sintática do recurso.

O objetivo deste artigo, no entanto, é analisar a presença dessa função enunciativo-discursiva quando assinalada por sinais de pontuação como travessões ou parênteses, cujos usos devem ser compreendidos para além das explicações que os associam à subjetividade de uma ênfase possivelmente pretendida por quem os aplica. Aliás, é um pouco disso o que se percebe em indicações e/ ou justificativas de uso do tipo: "às vezes, para dar maior realce a uma conclusão que representa a síntese do que se vinha dizendo, usa-se o TRAVESSÃO SIMPLES em lugar de DOIS PONTOS" (CUNHA; CINTRA, 2008, p. 682 - grifo do autor). Para superar as limitações dessa percepção, é necessário salientar que os sentidos das expressões intercaladas por travessões e parênteses remetem a outras instâncias do texto: aos aspectos enunciativo-discursivos. Nesse sentido, é preciso reconhecer a amplitude das considerações de Bechara (2003), que, em relação ao uso dos parênteses, ressalta que "vale lembrar, como fez Catach [sem data], que [os parênteses] assinalam um isolamento sintático e semântico mais completo dentro do enunciado, além de estabelecer maior intimidade entre o autor e o seu 
leitor" (BECHARA, 2003, p. 612). Nota-se, nessa justificativa de uso, a compreensão de que a potencialidade comunicativa desses recursos de pontuação desprende-se do aspecto sintático, colocando-se na "órbita" do enunciativo-discursivo. Essa potencialidade comunicativa dos travessões e parênteses, aplicados em situações específicas de uso, pode ser visualizada a partir da análise do fragmento 2 , logo abaixo:

(2) "Acho que nos Estados Unidos e nas sociedades ocidentais - e isso está baseado em estudos que eu cito no livro - tendemos a acreditar mais no talento quando se trata de capacidades acadêmicas" (BBC News Online, 2018).

De início, a partir da aplicação dos travessões duplos intercalando a expressão: "- e isso está baseado em estudos que eu cito no livro -", deduz-se a presença de dois aspectos fundamentais. $O$ primeiro diz respeito à ausência de interferência dos travessões na organização da estrutura sintática do fragmento. Essa ausência de intervenção no nível sintático pode ser demonstrada pela possibilidade de retirada dos travessões sem qualquer prejuízo aos aspectos sintáticos do fragmento; uma vez que a conjunção "e" conecta os dois segmentos oracionais constituidores do período. O segundo aspecto revela, nas palavras de Dahlet (2006), a presença de um "desengate enunciativo", promovido justamente pela presença dos travessões, que seccionam o enunciado em dois atos de linguagem. Neste ponto, é preciso fazer referência às definições de Charaudeau (2014), pelas quais ele delimita o ato de linguagem como um evento de interpretação do enunciado, mas que "depende 'dos saberes supostos que circulam entre os protagonistas da linguagem"' (CHARAUDEAU, 2014, p. 44). Para o autor, os sentidos do que se enuncia depende de um jogo entre explícito/implícito estabelecido entre os sujeitos envolvidos no evento comunicativo. Entende-se que esse jogo entre explícito/implícito não se limita apenas ao contexto em que está inscrito o enunciado, ele diz respeito também aos conteúdos selecionados e às formas como são apresentados na composição do evento comunicativo.

Naquilo que interessa para esta reflexão, a posição de Charaudeau (2014), aplicada às análises pretendidas aqui, ajuda a entender como no processo de escrita e de marcação do escrito - através dos recursos de pontuação - o escrevente assinala uma mudança de direção de sua atitude textual, isto é, de seu ato de linguagem. No caso do fragmento em questão (2), o período divide-se em duas partes fundamentais: a que não está intercalada pelos travessões, e a que se intercala entre eles. É esse procedimento de escrita que viabiliza o processo de 
desengate enunciativo. Os travessões evidenciam, portanto, a sobreposição de ações comunicativas distintas, que provocam o afastamento entre enunciado e enunciador exatamente naquilo que está intercalado pelos travessões. Assim, "a presença do marcado remete a uma postura do escritor" (DAHLET, 2006, p. 167). Se se considerar e se somar a isso o que diz Charaudeau (2014), pode-se deduzir também que a presença do marcado aciona - ao tempo que remete ao escrevente - as percepções do interpretante. Essa assinalação permite enxergar, no fragmento (2), dois atos comunicativos distintos: $1^{\circ}$ ) a "crença" nas capacidades acadêmicas (tudo que não está intercalado pelos travessões); $2^{\circ}$ ) e as referência não explicitadas, mas localizadas no livro (a expressão intercalada pelos travessões).

Visto isso, parece razoável a compreensão de que uma abordagem normativa sobre os usos dos sinais de pontuação não dê conta dessa sobreposição dos valores enunciativo-discursivos promovidos pelos travessões; mas não é igualmente razoável que se "negue" a estudantes da modalidade escrita da língua a possibilidade de reconhecer e compreender esse tipo de uso dos recursos de pontuação. Ademais, não é aceitável a perpetuação de explicações e justificativas dependentes de percepções subjetivas e imprecisas para fenômenos concretos, pertinentes e significativos, que estão fortemente presentes na vida dos usuários da modalidade escrita da língua. Segundo Dahlet (2006), para compreender o papel enunciativo dos recursos de pontuação, é preciso levar em consideração a existência de uma função diretora dos usos desses recursos. A partir desse entendimento, a autora defende uma categorização dos sinais de pontuação dividida em dois grupos: a) marca de sequência e b) marca de enunciação. Compreendendo-se como marca de sequência aqueles sinais que organizam a estrutura do texto, isto é, que delimitam, separam e hierarquizam suas partes; mantendo, portanto, o continuum textual.

Dahlet (2006) define ainda como marca de enunciação, os recursos de pontuação que "remetem não somente àqueles que indicam todas as formas de citação, como também aos que efetuam um 'desengate enunciativo' que [...] indica um distanciamento do enunciador em relação ao enunciado, do qual provém um efeito de sentido" (DAHLET, 2006, p. 51). Segundo essa perspectiva, estão compreendidos dentro da categoria de marcas enunciativas recursos de pontuação como dois-pontos, parênteses, travessões, ponto de interrogação, ponto de exclamação e as reticências. A autora sugere uma tipificação dessas marcas divididas em hierarquizadores discursivos, marcadores expressivos, marcadores interativos e marcas de discurso citado. Toda essa sistemática organização pode ser observada no quadro sinótico elaborado pela própria autora e reproduzido 
abaixo:

Marcas de sequência e marcas de enunciação

\begin{tabular}{|c|c|c|c|c|c|c|}
\hline \multicolumn{3}{|c|}{ Marcas de Pontuação de Sequência } & \multicolumn{4}{|c|}{ Marcas de Pontuação de Enunciação } \\
\hline Palavra & Frase & Texto & Discursiva & Expressiva & Interativas & Citação \\
\hline $\begin{array}{l}\text { Apóstrofo } \\
\text { Hífen } \\
\text { Ponto } \\
\text { Maiúscula }^{1}\end{array}$ & $\begin{array}{l}\text { Ponto } \\
\text { Vírgula } \\
\text { P. de } \\
\text { Interrogação } \\
\text { P. de } \\
\text { Exclamação } \\
\text { Reticências }\end{array}$ & $\begin{array}{l}\text { Alínea } \\
\text { Branco }\end{array}$ & $\begin{array}{l}\text { Dois-pontos } \\
\text { Parênteses } \\
\text { Travessão }\end{array}$ & $\begin{array}{l}\text { Maiúscula } \\
\text { Sublinhado } \\
\text { Itálico } \\
\text { Negrito }\end{array}$ & $\begin{array}{l}\text { P. de } \\
\text { Interrogação } \\
\text { P. de } \\
\text { Exclamação } \\
\text { Reticências }\end{array}$ & $\begin{array}{l}\text { Aspas } \\
\text { Itálico } \\
\text { Travessão } \\
\text { Colchetes }\end{array}$ \\
\hline
\end{tabular}

Fonte: (Dahlet, 2006, p. 167).

Ainda segundo Dahlet (2006), essas marcas de pontuação "[...] abarcam o campo de operações pontuacionais que, de uma maneira ou de outra, provém do marcado, do destacado" (DAHLET, 2006, p. 167). Nesse artigo, salienta-se que o "efeito de sentido", produzido a partir do emprego de uma marca enunciativa, imprime também ao segmento textual certa diretividade do ato de linguagem. Isso possibilita a identificação não só do distanciamento do enunciador em relação ao enunciado - como defende a autora -, mas também revela a intencionalidade, isto é, aquilo que pretende o enunciador ao provocar tal desengate enunciativo. Essa sobreposição de informações, marcadas por esse tipo de recurso de pontuação, é denominada, aqui, de marca de pontuação enunciativo-discursiva. Isso significa dizer que essas marcas enunciativo-discursivas, ao promoverem o distanciamento entre o enunciado e o enunciador, imprimem certo efeito de sentido, revelando comportamentos linguísticos intencionais possíveis de interpretação.

Diante disso, faz-se necessário dizer que, para além de toda a complexidade linguístico-filosófica que o termo intencionalidade possa despertar, satisfaz aos objetivos e pressupostos desta pesquisa a compreensão de que a intencionalidade se manifesta quando, diante da possibilidade de uso de diferentes recursos linguísticos, opta-se por um determinado tipo e não por outro. Nesse caso, entende-se que esse procedimento indica a busca por um determinado efeito de sentido, ainda que isso "transgrida" orientações normativas de uso dos recursos de pontuação. Nesse sentido, os contextos de comunicação e as condições de produção do enunciado permitem considerar que "desde esse ponto de vista, 
tudo quanto pode constituir a satisfação de uma intenção pode ser uma ação intencional" (SEARLE, 1995, p. 13).

Assim, a intencionalidade de um ato de linguagem poderá ser percebida e considerada, para efeito de análise, quando se puder identificar (explicita ou implicitamente) os possíveis efeitos de sentido provocados pela escolha e aplicação de um determinado - e não outro - recurso de pontuação. Considerando, portanto, o objetivo do trabalho desenvolvido e o tratamento dado aos fenômenos observados aqui, defende-se que essa manifestação de sentidos e, por conseguinte, de intencionalidades ocorre em várias situações de usos dos recursos de pontuação. Vale lembrar, no entanto, que o objetivo do estudo trazido para este artigo limita-se a analisar ocorrências que envolvam apenas dois desses recursos: travessões e parênteses.

\section{Análises das ocorrências}

Por conta de restrições metodológicas e da própria natureza do gênero textual em que se insere este artigo, serão analisados os usos de parênteses e travessões em duas ocorrências coletadas em publicações de portais de notícias. As análises partem do pressuposto de que esses dois tipos de pontuação - em situações específicas de uso - promovem, como defende Dahlet (2006), um desengate enunciativo; ao tempo em que marcam, segundo a hipótese proposta neste trabalho, a presença de posturas discursivas significativas. Essa mudança de função revela sua transmutação em recursos discursivos, pois passam a funcionar como indicadores da presença de intencionalidade, ou seja, apontam certa diretividade na escolha do recurso assinalado. Esse processo manifesta-se, por exemplo, no uso dos parênteses na legenda da Imagem 1, abaixo, que corresponde à primeira ocorrência analisada aqui:

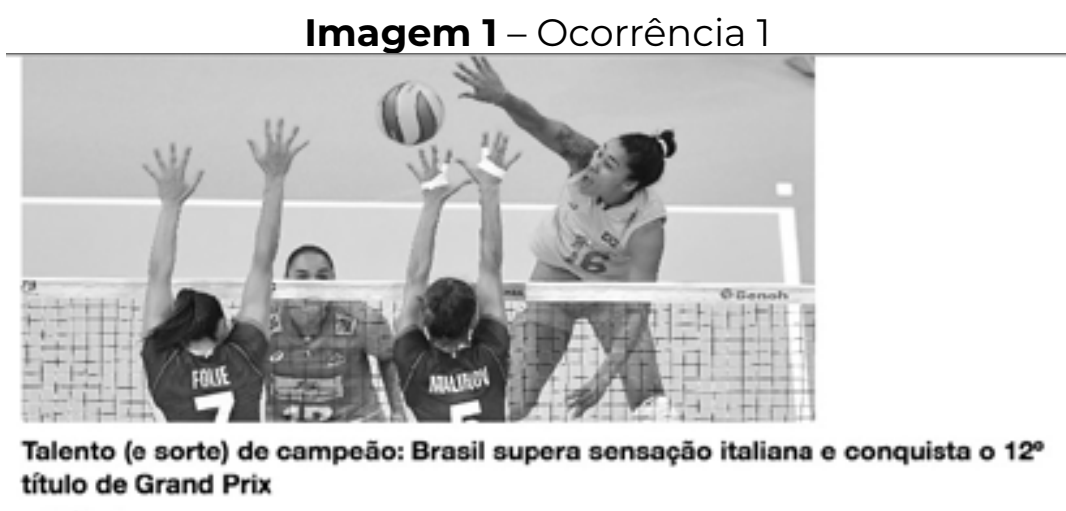

Fonte: (FACERJ online, 2017). 
Como se viu no caso apresentado no tópico anterior (a título de exemplificação), a primeira observação importante é que, do ponto de vista sintático, os parênteses são absolutamente dispensáveis para a estruturação do período, pois a conjunção "e" (colocada dentro da intercalação) exerceria essa função satisfatoriamente, coordenando os substantivos "talento e sorte". Constatado isso, pode-se perguntar - a fim de se compreenderem os efeitos de sentidos obtidos - o que pretendia o autor ao aplicar os parênteses numa situação em que eles seriam visível e sintaticamente dispensáveis? Uma reflexão inicial aponta que a presença dos parênteses promove o "desengate enunciativo que ocorre quando um desses topogramas ${ }^{3}$ indica um distanciamento do enunciador em relação ao enunciado, do qual provém um efeito de sentido" (DAHLET, 2006, p. 51). Esse primeiro aspecto já justificaria a aplicação dos parênteses enquanto marca de pontuação enunciativa, cuja função seria assinalar o distanciamento dos planos enunciativos. Para além dessa função, é preciso compreender que "a separação, entretanto, agora não se processa entre os segmentos da cadeia sintática, mas em um plano mais alto - entre os locutores ou pontos de vista presentes na situação comunicativa" (JUNKES, 2002, p. 66).

A função enunciativa, nessas situações de uso dos sinais de pontuação, produz um efeito de sentido que consiste na marcação de uma sobreposição de atos comunicativos, isto é, aquilo que está posto fora dos parênteses é, comunicativamente, diferente daquilo que se encontra intercalado por eles. Assim, na frase em questão, os parênteses intercalam um ato de linguagem que se sobrepõe àquele que, objetivamente, enuncia o "talento de campeã". Portanto, pode-se perceber que os parênteses não estão sendo usados simplesmente para "isolar palavras, locuções ou frases intercaladas no período" (CEGALLA, 2008, p. 233), esse "isolamento" parece bastante óbvio pela própria natureza tipográfica do recurso e pela disposição das expressões no segmento textual. Entende-se, portanto, que os parênteses estão assinalando, na realidade, a presença de dois comportamentos linguísticos num mesmo enunciado, que são: o "talento de campeã", objetivamente enunciado; e a "(sorte) de campeão" circunstancialmente assinalada pelo olhar de quem enuncia.

Uma maneira possível de serem atestadas tais inferências, promovidas pela forma de pontuar o segmento, é reescrevendo o fragmento sem os parênteses, ou os substituindo por outros recursos de pontuação de mesmo valor, ou

3 Dahlet, citando Jacquis Anis (1988), apresenta os recursos de pontuação em três categorias alfagrama, topogramas e logogramas. Por topogramas, entende-se os sinais que "ordenam [...] as unidades textuais, fornecem indicações sintagmáticas indispensáveis" (ANIS apud DAHLET, 2006, p. 42) 
de valor aproximado. Dessa forma, será possível verificar mudanças significativas nos efeitos de sentido produzidos por tais marcações. Assim, aplicando-se algumas possibilidades de reconfiguração do fragmento, obtém-se a seguinte proposta de reescrita (A):

A. Talento e sorte de campeã: Brasil supera sensação italiana e conquista o $12^{\circ}$ título do Grand Prix.

Nesse caso, a ausência de parênteses ou de qualquer outro recurso de pontuação faz com que as expressões "talento" e "sorte" sejam compreendidas como pertencentes ao mesmo ato comunicativo, isto é, como se fizessem naturalmente parte dos fatos noticiados. Isso implica desconsiderar, de início, o desengate enunciativo, que revelou (no texto-fonte) o distanciamento enunciado/ enunciador. Nessa configuração, a conjunção "e", porém, não potencializa a percepção do aspecto avaliativo presente no uso do substantivo "sorte", em oposição ao aspecto mais descritivo e objetivamente apontado pelo uso do termo "talento". Entende-se, pois, que apenas o uso da conjunção (certamente a construção mais esperada e mais comum) deixaria a informação no âmbito da mera descrição do fato noticiado. No texto-fonte, no entanto, a presença dos parênteses potencializou a manifestação e a percepção de duas atitudes discursivas distintas: a informação mais objetiva (tudo que está posto fora dos parênteses), em oposição à postura mais subjetiva e avaliativa (entre parênteses). É importante lembrar que a opção por parênteses, nesse tipo de construção, não é sequer prevista nos manuais gramaticais, uma vez que o mecanismo de conexão sintático já está presente.

Numa outra proposta de reescrita (B), em que se aplicam travessões no lugar dos parênteses, tais recursos parecerão igualmente aceitáveis por promoverem também um desengate enunciativo e assinalarem uma diretividade dos sentidos pretendidos. Isso implica considerar que tudo está posto muito semeIhantemente ao que se verifica com o uso dos parênteses no texto-fonte.

B. Talento-e sorte-de campeã: Brasil supera sensação italiana e conquista o $12^{\circ}$ título do Grand Prix

Favorece essa reescrita o fato de que - ao contrário do que acontece com o uso dos parênteses - os travessões mantêm as duas partes do enunciado no mesmo nível de expressividade; ou seja, a constatação de "talento" (objetivamente apresentada) e a atribuição de "sorte" (subjetivamente assinalada) encontram-se expressas naquilo que há de mais imediato no texto. A análise desse emprego de pontuação evidencia que os parênteses (no texto fonte), além do desengate 
enunciativo, retiram o segmento intercalado do mesmo nível de expressividade, como se o remetesse a outro plano de informação, diferente e menos imediato do que aquele em que se encontra o resto da frase.

Ainda na proposta de reescrita acima (B), os travessões indicam a presença de dois atos comunicativos que estão sendo colocados num mesmo nível de importância para aquilo que se quer efetivamente comunicar. Pode não parecer significativo, mas essas distinções de aspectos e de funções revelam posturas discursivas bastante específicas no ato de escrita e que se espera poder serem "traduzidas" durante os processos de leitura e compreensão do enunciado. Julgam-se essas particularidades e distinções importantes, porque é preciso considerar que a existência dessas possibilidades de pontuação não se resume ao simplesmente comutável ou permutável, isto é, às pertinências e particularidades de cada recurso de pontuação não podem ser ignoradas, ou tratadas como simplesmente equivalentes, uma vez que sua própria coexistência deve suscitar a existência de especificidades.

Ademais, no caso do texto-fonte, ao optar pelo uso dos parênteses, o autor do texto faz uma escolha intencional, portanto, discursiva, pela qual sinaliza uma tomada de postura que, certamente, corrobora aquilo que será descrito e comentado ao longo da matéria jornalística, que noticia a vitória da Seleção Brasileira de Voleibol sobre a Seleção Italiana. É fundamentalmente importante observar que esse tipo de uso de parênteses não é assim apresentado na maioria dos manuais gramaticais. Constata-se que em algumas indicações de uso desse recurso tende-se à apresentação de explicações imprecisas ou generalizantes dos critérios de aplicação.

Em Bechara (2003), nota-se claramente que não há uma preocupação em descrever ou formular critérios para o uso desse recurso de pontuação. A mesma postura é verificada em Lima (1992), o qual sequer apresenta os parênteses entre os tópicos descritos como sinais de pontuação - embora os apresente no quadro geral como "um sinal de pausa que não quebra a continuidade do discurso" (LIMA, 1992, p. 457). Para esses dois gramáticos, a formulação do tópico resume-se praticamente ao que está reproduzido na citação acima. Parece evidente que qualquer usuário da modalidade escrita da língua que necessite de orientações para uma adequada aplicação desses recursos não poderia fazer uso eficiente desses "critérios", pois, certamente, não se sentiria seguro para aplicá-los numa situação real de construção textual.

Não obstante, em Cunha e Cintra (2008), percebe-se a indicação e a apre- 
ciação de aspectos que se encontram fora dos limites do puramente sintático na aplicação desse tipo de recurso de pontuação. Em suas palavras,

empregam-se os PARÊNTESES para intercalar num texto qualquer indicação acessória. Seja, por exemplo: a) uma explicação dada ou uma circunstância mencionada incidentalmente [...]; b) uma reflexão, um comentário à margem do que se afirma [...] (CUNHA; CINTRA, 2008, p. 679 - grifo do autor).

Apesar de sua compreensão de funções mais abrangentes para esse tipo de recurso, é necessário fazer alguma ressalva em relação a essa forma de descrever os usos dos parênteses, pois nota-se também certa imprecisão e/ou generalização em suas indicações, uma vez que os autores não justificam o que se deve entender por "circunstância mencionada incidentalmente", "comentário" ou "nota emocional". É importante salientar, porém, que suas observações se distinguem das de Bechara (2003) e Lima (1992), pois denotam a percepção de que esse é um tipo de recurso de escrita, cujos usos podem extrapolar a consideração de aspectos puramente sintáticos.

A segunda ocorrência analisada destaca-se pela forma como o travessão é aplicado para separar, em duas partes distintas, um enunciado que (a exemplo da primeira ocorrência) já apresenta um elemento conectivo no nível da estrutura sintática. A partir da própria configuração sintática do texto, pode-se perceber como os travessões são tomados como um recurso de pontuação de uso equivalente aos parênteses.

Imagem 2 - Ocorrência 2:

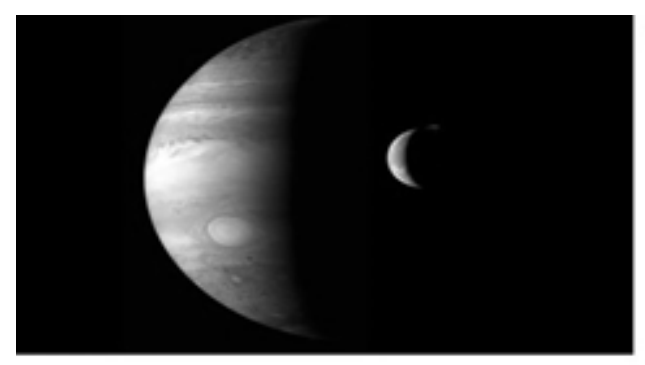

Descobertas 12

novas luas em

Júpiter - e uma

delas é uma pedrinha suicida

Com essa nowa dúzia de astros, Jüpiter passa a ter 79 satélites. Um deles tem um quilometro de diametro - e pode trombar com as demais a qualquer

Fonte: (Revista Superinteressante online, 2018)

Na frase destacada (em negrito e fonte maior), vê-se que o travessão deixou de ser mera sinalização sintática para indicar o desengate enunciativo e, por conseguinte, marcar aspectos discursivos específicos presentes em cada uma das orações que compõe o período. Nesse sentido, ele passa a assinalar níveis 
de expressividade distintos entre o que está posto antes e o que aparece entre a intercalação (embora não seja o caso de travessões duplos); revelando atos de linguagem distintos e, por conseguinte, intencionalidades específicas. Essas funções podem ser deduzidas, a exemplo do que aconteceu com os parênteses na ocorrência anterior, a partir de propostas de reescrita em que o travessão possa ser substituído por outro recurso de pontuação, ou até mesmo ser subtraído da frase. Na primeira proposta de reescrita $(A)$, tem-se a seguinte situação:

A. "Descobertas 12 novas luas em Júpiter, e uma delas é uma pedrinha suicida".

Com a vírgula substituindo o travessão, tem-se uma situação de uso de pontuação prevista nos manuais gramaticais. Segundo Azeredo (2008), "nas orações introduzidas pela conjunção e, pode-se empregar a vírgula: quando apresenta sujeitos diferentes, principalmente se temos a intenção de enfatizá-los" (AZEREDO, 2008, p. 520 - grifo nosso). Essa é uma orientação de uso de vírgula bastante conhecida; neste caso, porém, o gramático salienta a marcação da ênfase, que, a rigor, não aponta para uma função objetivamente compreensível. Além disso, o uso da vírgula não imprime à forma escrita a expressividade capaz de provocar o desengate enunciativo responsável por revelar o distanciamento do enunciador em relação ao enunciado. Percebe-se também que, com a ausência do travessão, e a vírgula funcionando como recurso sintático, perde-se a marcação da intencionalidade do ato de linguagem particular e distintivo que está contido na segunda oração do período.

Numa segunda proposta de reescrita (B), na qual o travessão é subtraído e a conjunção é mantida como elemento conectivo entre as duas orações do período (sem a vírgula), nota-se a ausência do efeito de desengate enunciativo e, portanto, de mudança do nível de expressividade. Assim, o ato de linguagem caracterizador da primeira oração do período poderá ser tomado como equivalente ao que constitui a segunda oração, isto é, não se fará a distinção entre o que é, objetivamente enunciado (a notícia) e aquilo que compõe o comentário. Nessa proposta, o período terá a seguinte configuração:

B. "Descobertas 12 novas luas em Júpiter e uma delas é uma pedrinha suicida".

Considerando-se que essa configuração - juntamente com a proposta de reescrita anterior $(A)$ - pode corresponder a uma das formas de escrita mais frequente; no entanto, a simples presença da conjunção como elemento coesivo 
não habilitará a leitura dos atos de linguagem distintivos que compõem o fragmento. Isso significa dizer que, como recurso sintático-textual, a conjunção não será capaz de assinalar para a efetiva interpretação do segmento nem no que diz respeito ao desengate enunciativo nem à mudança do nível de expressividade. Dessa forma, portanto, o leitor não será "alertado" para o fato de que o conteúdo informativo da primeira oração do período (a descoberta) se caracteriza como uma notícia; enquanto que o conteúdo da segunda oração (comentário) identifica-se como uma forma alegórica - talvez irônica, ou jocosa - de se lidar com o conteúdo da notícia propriamente dito. No texto-fonte, ao aplicar o travessão como marca enunciativo-discursiva de pontuação, o autor da frase deixa assinalada a mudança de atitude textual e os diferentes níveis de expressividade entre as duas partes do enunciado, seccionando o período em duas enunciações distintas no que diz respeito à natureza discursiva expressa por cada uma das orações que constitui o período.

Nesse sentido, percebe-se que o autor do texto opta por duas enunciações, articuladas numa mesma estrutura frasal. Como já dito, uma dessas informações pertence à órbita dos fatos (a notícia) - e precisa ser transmitida objetivamente -, a outra revela uma "leitura", uma forma específica e autoral do jornalista noticiar. Note-se que por conta dessas características discursivas, a segunda frase distancia-se da objetividade esperada numa notícia; inclusive, sinaliza para traços estilísticos com efeitos de uma certa ironia: "pedrinha suicida". A opção de não assinalar essas distinções por meio de recurso de pontuação (sem travessão) esvazia o potencial comunicativo da sentença no que se refere à leitura dos comportamentos enunciativos e à percepção das intencionalidades discursivas manifestadas nos seus efeitos de sentido.

\section{Considerações finais}

Levando-se em conta o que foi dito sobre as duas ocorrências analisadas aqui, é possível perceber que os diferentes recursos de pontuação se distinguem a partir de suas funções específicas, seja na organização das estruturas sintáticas do texto, seja na elaboração discursiva dos enunciados. Essas constatações permitem compreender o quanto é temerária a pressuposição de que a aplicação dos recursos de pontuação está associada à transposição de aspectos da fala para escrita, ou de que tais recursos de escrita se equivalem e que, por isso, são simplesmente permutáveis e dependentes de escolhas subjetivas e ocasionais 
de quem os aplica. Dito isto e considerando aquilo que foi exposto neste artigo - mesmo restringindo as análises das ocorrências apenas ao uso de parênteses e travessões -, é possível notar as especificidades assinaladas em torno das informações intercaladas por esses dois tipos de recursos de pontuação. É possível observar também o modo como tais especificidades fazem sobressair aspectos lógico-linguísticos inerentes aos usos desses recursos.

As análises apresentadas procuraram explicitar como os usos e os critérios de aplicação dos sinais de pontuação devem ser considerados para além de aspectos prosódicos e, principalmente, dos sintáticos. A presença de um desengate enunciativo e a consequente produção de efeito de sentido provocada pela aplicação de parênteses e/ou travessões são dois fenômenos particulares explorados neste trabalho. Isso significa dizer que é preciso compreender as funções desses recursos de pontuação como verdadeiras marcas enunciativo-discursivas, uma vez que são capazes de promover interpretações específicas dos conteúdos por elas intercalados. Já os sentidos decorrentes de seus usos são compreendidos a partir das distinções entre a consideração do que se evidencia com ou sem a presença de tais recursos de pontuação. A superação de um aspecto puramente sintático parece clara quando se observa a dupla utilização de recursos como travessão e vírgula (-,), bem como de parênteses e vírgula ou ponto (como se vê aqui, nesta frase).

Todos os aspectos descritos e analisados ao longo deste artigo revelam a presença de propriedades enunciativo-discursivas resultantes do processo de transmutação dos sinais de pontuação (travessões e parênteses) em marcas enunciativo-discursivas de pontuação. Este processo está caracterizado a partir do momento em que tais recursos deixam de exercer funções sintático-textuais e passam a indicar funções enunciativo-discursivas. Quanto à estratégia de usar textos jornalísticos, pertencentes ao gênero notícia, serviu para evidenciar que tais fenômenos estão presentes em situações corriqueiras de comunicação escrita e que são acessíveis aos mais diversos perfis de público leitor. Isso significa reconhecer que não se trata de recursos estilizados ou pertencentes a gêneros rebuscados como os literários e os acadêmicos, o que mostra também que são formas legítimas e eficazes de se manifestar mais do que as expressões verbais são capazes de explicitar.

Diante de tudo isso, julga-se necessário e indispensável a exploração sistemática desses aspectos nos processos de leitura e compreensão textual. Os usuários da modalidade escrita da língua precisam estar aptos, portanto, para a leitura 
do sistema simbólico de representação que se materializa também nos usos dos recursos de pontuação, sejam eles considerados sinais de pontuação - com implicações na organização sintático-estrutural do texto -, sejam eles considerados marcas enunciativo-discursivas de pontuação, que se referem aos efeitos de sentido decorrentes de sua aplicação.

\section{Referências}

AZEREDO, José Carlos. Gramática Houaiss da língua portuguesa. 2. ed. São Paulo: Publifolha, 2008.

BARBIER, Fréderic. História do livro. São Paulo: Paulistana, 2008.

BECHARA, Evanildo. Moderna gramática portuguesa. 37. ed. Rio de Janeiro: Editora Lucerna, 2003.

CASTEDO, Antía. As surpresas do ensino de Xangai, um dos mais desconhecidos (e bem-sucedidos) do mundo. Disponível em: https://www.bbc.com/portuguese/internacional-45426702. Acesso em: 20 maio 2020.

CATACH, Nina. La punctuation: histoire et systeme (que sais-je). 2. ed. Paris: Universitaires de France, 1994.

CEGALLA, Domingos Paschoal. Novíssima gramática da língua portuguesa. 48. ed. São Paulo: Companhia Editora Nacional, 2008.

CHARAUDEAU, Patrick. Linguagem e discurso: modos de organização. 2. ed. São Paulo: Contexto, 2014.

CUNHA, C.; CINTRA, L. F. L. Nova Gramática do Português Contemporâneo. 5. ed. Rio de Janeiro: Lexikon, 2008.

DAHLET, Véronique. As (man)obras da pontuação: usos e significações. São Paulo: Associação Editorial Humanitas, 2006.

FACERJ. Talento (e sorte) de campeã: Brasil supera sensação italiana e conquista $12^{\circ}$ título de Grand Prix. Disponível em: http://facerj.org.br/talento-e-sorte-de-campeao-brasil-supera-sensacao-italiana-e-conquista-o-12o-titulo-de-grand-prixl. Acesso em: 20 maio 2020.

HALLIDAY, Michael A. K. 1989. Spoken and written language. 2. ed. England: Oxford University Press, 1989.

HOUAISS, Antônio. Elementos de bibliografia. V. I. São Paulo: HUCITEC, 1983.

JUNKES, Terezinha Kuhn. Pontuação - uma abordagem para a prática. Florianópolis: Editora UFSC, 2002.

LIMA, Carlos H. Rocha. Gramática normativa da língua portuguesa. 31. ed. Rio de Janeiro: José Olympio, 1992. 
MARCHADO FILHO, A. Venâncio Lopes. A pontuação em manuscritos medievais português. Salvador: EDUFBA, 2004.

SEARLE, John. Intencionalidade. São Paulo: Martins Fontes, 1995.

TRASK, R. L. Dicionário de linguagem e linguística. São Paulo: Contexto, 2008.

VAIANO, Bruno. Descoberta 12 novas luas em Júpiter - e uma delas é uma pedrinha suicida. Disponível em: https://super.abril.com.br/ciencia/descobertas-12-novas-luas-em-jupiter-e-uma-delas-e-uma-pedrinha-suicidal. Acessado em: 20 maio 2020.

VENTURA, Dalia. Grigori Perelman, o gênio que resolveu um dos maiores problemas matemáticos do milênio e 'sumiu do mapa'. Disponível em: https://www.bbc.com/portuguese/ geral-48521904. Acessado em: 20 maio 2020.

\section{Sobre os autores}

Antonio Cesar da Silva - Doutorando na Universidade Federal de Alagoas (UFAL), doutorando no Programa de Pós-Graduação de Linguística e Literatura (PPGLL) e professor assistente na Universidade Estadual de Alagoas (UNEAL), curso de Letras/ Português, Campus IV, São Miguel dos Campos - AL. E-mail: ancesil16@gmail.com; Lattes: http://lattes.cnpq.br/7638616650455105; Orcid: https://orcid.org/0000-0002-6147-0802.

Maria Inez Matoso Silveira - Professora doutora aposentada voluntária, pesquisadora do quadro do Programa de Pós-Graduação em Linguística e Literatura (PPGLL) da Universidade Federal de Alagoas (UFAL), Campus A.C. Simões Maceió - AL. E-mail: mimatoso@uol.com.br; Lattes: http://lattes.cnpq.br/1877904100434370; Orcid: https:// orcid.org/0000-0002-2776-150X. 